\title{
Modelo de doble tensión para analizar las estrategias de reconocimiento pleno de las diversidades sexuales en los debates de ciudadanía
}

\author{
Claudia M. Hurtado-Caycedo*
}

\author{
Nivel: Comunicado \\ Fecha de recepción: 20 de julio de 2011 \\ Fecha de aprobación: 1 de septiembre de 2011
}

\begin{abstract}
Resumen
El artículo argumenta que al menos en el contexto colombiano, los reconocimientos de las diversidades sexuales son limitados por negociarse preponderantemente en un campo político de tipo jurídico. En otras palabras, las limitaciones para lograr una real ciudadanía igualitaria pueden ser parcialmente atribuibles a que los debates se localizan en un campo que reconoce la dimensión jurídica, a la vez que desconoce la dimensión simbólica, y en la misma línea, reduce la sociedad política a la institución estatal.

Se propone un modelo de análisis de doble tensión que desplaza la discusión al campo de la ciudadanía, el cual se construye en la relación Estado - Sociedad Civil, y en el que también se reconoce la dimensión simbólica de lo que cuenta como político. Encuadrado en este modelo hace un seguimiento de la potencia que tiene la Marcha de la Ciudadanía Plena LGTB para ampliar la noción de ciudadanía, incluyendo las diversidades sexuales.
\end{abstract}

Palabras clave: Ciudadanía, Diversidad Sexual, LGTB.

\begin{abstract}
In this article I argue that, at least in the Colombian context, incorporating sexual diversity through the Constitutional Court is a limited resource. In other words, the difficulties to reach an actual equal-rights citizenship might be attributed in part to the fact that the debate is being held limited to a legal ground and community. Accordingly, I propose an analysis based on a "double-tension" model that shifts the discussion towards citizenship, which is a field that is built in the relationship between the State and the civil society (civilians). Moreover, it is also in this field that the symbolic dimension of what is considered "political" is recognized. Framed in this this "double-tension" model, I present a discussion of the influence that a movement entitled "Marcha de la Ciudadanía Plena LGBT" has had in terms of extending the notion of citizenship, to include the sexual diversities.
\end{abstract}

Key words: Citizenship, Sexual Diversity, lgbt.

* Psicóloga de la Universidad de los Andes, Magíster en Estudios Culturales de la Pontificia Universidad Javeriana, Bogotá, Colombia. Trabaja los temas de sexualidades, género y ciudadanía. Actualmente gestiona y promueve proyectos con la Pontificia Universidad Javeriana, el IESCO de la Universidad Central y Canal91. org, claudiahurtadoc@yahoo.com 
Modelo de doble tensión para analizar las estrategias de reconocimiento pleno de las diversidades sexuales en los debates de ciudadanía - Claudia M. Hurtado-Caycedo

\section{Introducción}

Holanda, Bélgica, España, Canadá, Sudáfrica, Portugal, Noruega, Suecia, Islandia, Brasil, Argentina, México D.F., y Estados Unidos, son los países que han aprobado el matrimonio entre personas del mismo sexo. La Convención Europea, por su parte, determinó que el derecho a casarse ya no es privativo de las parejas heterosexuales y dejó la determinación a cargo de cada Estado. Colombia se sumará a este listado en dos años, plazo que tiene el Congreso para regular todo lo relacionado con la materia a fin de subsanar el déficit de protección a las parejas del mismo sexo, con la libertad de denominar este tipo de "vínculos jurídicos solemnes" con un nombre distinto al de matrimonio (Noguera Rojas, 2011). Es decir, al cabo de este período en Colombia existirá el matrimonio igualitario equiparable en derechos, aunque no necesariamente en denominación.

El tema a nivel internacional ha sido objeto de las decisiones judiciales a manos de las Cortes Supremas o Constitucionales, y la expedición de normas por parte del Poder Legislativo. En la primera parte de este texto planteo que, al menos para el caso colombiano, ambas aproximaciones tienen serias limitaciones. Posteriormente, propongo un modelo para analizar las estrategias de reconocimiento pleno de las diversidades sexuales en los debates de ciudadanía. Para finalizar, en el marco de este esquema, presentaré una alternativa que complementa y corrige las limitaciones de la aproximación jurídica, una apuesta en la que la confluencia de diferentes formas de organización colectiva, grupos, redes y espacios instituidos ganados tiene la potencia para ampliar el canon de la ciudadanía, incluyendo las diversidades sexuales. Me refiero a la Marcha de la Ciudadanía Plena LGTB (personas lesbianas, gays, bisexuales y transgeneristas), celebrada desde hace 30 años en Bogotá, Colombia; creo que ésta tiene la potencia para mostrarnos cómo se entrelazan de manera compleja, cambiante y tensionada la sexualidad y la ciudadanía. 
Para el caso de Colombia, los reconocimientos de las diversidades se han negociado preponderantemente en un campo político de tipo jurídico que, además, restringe la participación al Estado. Por ejemplo, el texto de Julieta Lemaitre Ripoll (2009): El derecho como conjuro, es guiado por una interrogante que acompaña a la activista legal y feminista: si el derecho parece impactar tan poco la violencia y la pobreza, ¿cómo se explica la fe que parecen tener en aquel tantos ciudadanos? El estudio da cuenta del uso que los movimientos sociales dan al derecho para generar significados sociales que rechacen la violencia física como parte de la red de significados del campo político. Lo más interesante del análisis es la propuesta de pensar el papel del derecho, primero, en estrecha relación con la violencia y, segundo, prestando especial atención a la forma como ambos luchan por crear significados sociales en la vida colectiva.

Para el caso particular de la población de personas lesbianas, gays, bisexuales y transgeneristas, la autora considera que el significado de las uniones civiles ${ }^{1}$ se imbrica con la violencia ejercida contra esta población, de tal modo que dicha unión tendría un significado menos paradójico y más "normal" de no ser por su coexistencia con las uniones legales de parejas del mismo sexo. En esta línea, su análisis considera el amplio espectro de violencias que coexisten con los derechos, que va desde:

Las miradas, las risitas, la pérdida de empleos y de trabajo, la preocupación y presión por parte de familiares y amigos, su rechazo, la necesidad de disimular, de esconder las emociones, el humor, la tristeza, la vida misma, y la corriente viciosa del odio que permea gestos al parecer inocentes, comentarios que se pretenden ligeros, y grafitis que se borran con el tiempo (Lemaitre, 2009:257).

Y llega hasta las amenazas de muerte, las palizas, los maltratos policiales, la extorsión, los abusos de las autoridades, el

\footnotetext{
1 Sentencia de la Corte Constitucional C-075 de 2007, que dio a las parejas del mismo sexo que cohabitan la posibilidad de crear una comunidad de bienes, tal y como pueden hacerlo las parejas heterosexuales.
} 
robo, la tortura, la violación, el asesinato y las atrocidades contra personas homosexuales.

Pese a la persistencia de la violencia, lo que Lemaitre Ripoll destaca es el significado simbólico de "los derechos [que] no niegan que la violencia exista, sino que niegan sus efectos interpretativos, los significados sociales que construyen. Así, mientras la violencia persiste en su afirmación de que [las personas] homosexuales merecen castigo público y privado por serlo, los derechos niegan que eso sea cierto" (Lemaitre, 2009: 256).

Reconozco la importancia que tiene ese significado simbólico; sin embargo, la realidad es que la violencia persiste. Es decir, si bien coincido en su apreciación sobre la importancia del respaldo de la ley, quiero señalar que esos pronunciamientos no cambian los aspectos simbólicos que subyacen a las discriminaciones. Pretender que lo hacen supone la simplificación de la realidad evidente, por ejemplo, negando las condiciones históricas y estructurales de discriminación de nuestra sociedad. Como lo expresaba Ángela Davis (2010), la importante activista del Black Feminism, en su visita a Bogotá, la institución carcelaria transmite la idea de que la sociedad se libra de la responsabilidad al recluir los inconvenientes en "ese lugar" al que pertenecen las personas malas. Pero, en el caso de la violencia homofóbica, ¿cómo tuvo esa persona responsable del crimen, la idea de que la solución está en erradicar a las personas sexualmente diversas? Para Davis, y coincido con ella, no se trata de una idea que el criminal pensó por sí mismo. Es decir, las limitaciones en el proceso hacia la real aceptación de las diversidades subsisten a pesar de que estos temas se estén negociando en el campo jurídico.

A mi parecer, además de esta limitación, hay otro inconveniente que voy a explicar brevemente. Los mencionados pronunciamientos son básicamente formulados e implementados por y desde instancias estatales. Reconociendo la importancia de que el matrimonio igualitario esté siendo estudiado por la Corte, consi- 
dero que es una estrategia limitada en la medida en que se dirige a conquistas en el terreno jurídico. Plantear la negociación en estos términos continúa una interlocución restringida con una sociedad política de tipo estatal. Aun cuando hay valiosos recursos de injerencia, como por ejemplo, las intervenciones ciudadanas que respaldaron la demanda, éstas deben ajustarse, en mayor o menor medida, a los términos jurídicos, haciendo necesario tener conocimientos o recursos para contratar a alguien que los tenga y además deben ser presentadas en un estrecho margen de tiempo tras la demanda. Es decir, el debate del matrimonio igualitario está circunscrito a un ámbito y términos jurídicos que limitan la participación de la sociedad civil.

Pensemos por ejemplo que este texto pasó por una revisión que constató la información de carácter jurídico; es decir que, como ciudadana, estoy medianamente facultada para presentar mi postura; en la misma línea, mi simple carácter de ciudadana no es suficiente para intervenir jurídicamente en la medida en que estoy obligada a participar en los términos propios de este campo. Considerando esta restricción, tenemos que preguntarnos por la pertinencia de desarrollar el debate acerca del matrimonio igualitario preponderantemente en esta instancia: ¿Los términos del debate hacen posible construir una legislación representativa de lo que nosotros queremos?

Retomando, las limitaciones en el proceso hacia la real aceptación de las diversidades son atribuibles, en alguna medida, precisamente al hecho de que las negociaciones se dan preponderantemente en un campo político de tipo jurídico que, además, restringe la participación.

Yo propongo un modelo de doble tensión para analizar las estrategias de reconocimiento pleno de las diversidades sexuales en los debates de ciudadanía, con el cual busco dejar de privilegiar el ámbito jurídico, así como el actor estatal, ubicando el análisis en la tensión entre el ámbito jurídico y el simbólico, por un lado; y entre el Estado y la sociedad civil, por el otro. En un cruce 
de tensiones en donde no hay una simple lucha entre los actores por la inclusión en uno u otro ámbito, sino la constitución de la ciudadanía como un complejo campo de lucha donde se superponen y funcionan en tensión y con contradicciones.

Figura 1: Modelo de doble tensión: en un eje, el Estado y la sociedad civil, y en el otro, el ámbito simbólico y el jurídico.

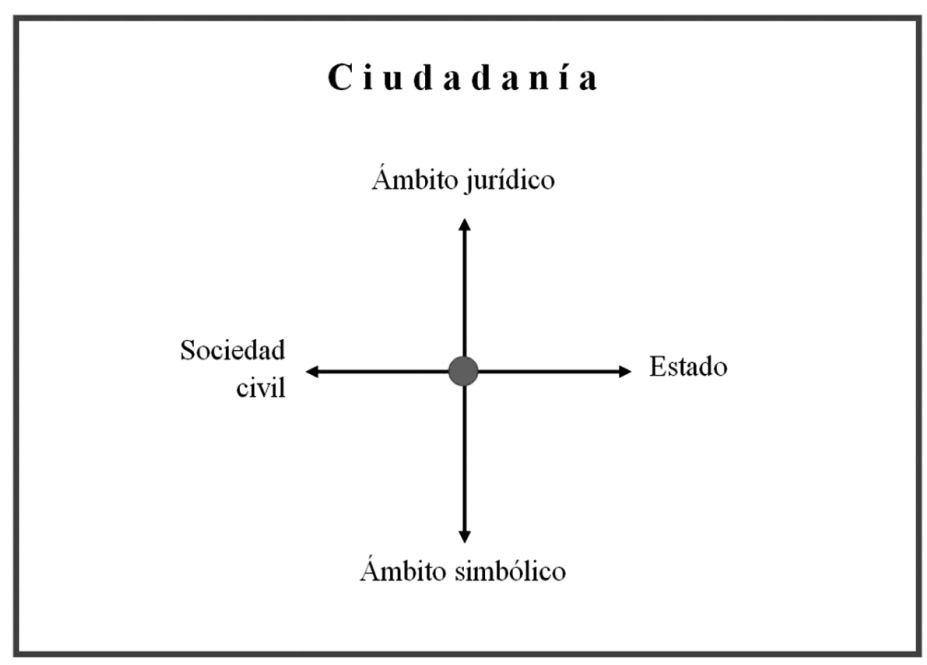

Este modelo sigue la consigna de los estudios culturales en particular y de la crítica a la razón ilustrada en general, de abandonar los binarismos al repensar los problemas sociales contemporáneos, así como las intervenciones para remediarlos. En este caso, ¿cómo incorporar las diversidades sexuales a la definición de ciudadanía?

Por otro lado, este modelo tiene la ventaja de definir la ciudadanía como un campo de lucha que se da en la relación Estadosociedad civil para definir lo que cuenta como "político" tanto en lo jurídico como en lo simbólico. En este sentido, es deudor del concepto de hegemonía de Gramsci: "una forma de dominación en la cual la coerción y la violencia no desaparecen, pero sí coexisten con formas de aceptación del poder y la dominación, más o menos voluntarias o consensuales por parte de los sujetos subalternos" (Aguirre, en Szurmuck y Mckee, 2009: 124). 
Este modelo resulta pertinente porque al hablar de pugna le imprime un carácter dinámico al proceso de definición de la ciudadanía. Asimismo, es relevante porque permite involucrar a diversos actores en el desafío por definir ciudadanías sexualmente diversas. Por un lado, al Estado (sociedad política) y, por el otro, a la sociedad civil. Ademas, es un concepto clave porque alude a los grupos subalternos que, en este caso, es la población sexualmente diversa y su papel activo para ampliar la ciudadanía más allá de la heteronormatividad sexual. Finalmente, permite instalar el análisis de la ciudadanía en la articulación entre formas jurídicas del poder por un lado, y simbólicas por el otro.

Ubico el modelo en la ciudadanía porque la doble tensión se instala en ella. Recordemos que la noción reestructuró radicalmente las relaciones políticas inaugurando la promesa de democracia al dejar atrás la figura del vasallo y su relación con el soberano, y por introducir un nuevo régimen entre ciudadanos y Estado liberal, lo que significó a su vez nuevos derechos y obligaciones (Grupo de Investigación Ciudadanías Incluyentes, en Vignolo, 2009). En otros términos, la ciudadanía se establece por la relación Estado-ciudadano, es decir, que se instituye en el marco y por efecto del Estado liberal y la promesa de la democracia.

Por otro lado, la historicidad del concepto da cuenta de un proceso en construcción. Pensemos por ejemplo en las constituciones republicanas de la Nueva Granada, en las que se estableció el tránsito de la sociedad de vasallos, en la cual las jerarquías dependían de la limpieza de sangre, a una sociedad de ciudadanos varones y blancos con igualdad de derechos: mientras que los varones pobres o analfabetos y los indígenas, recibieron plazos para cumplir los requisitos para convertirse en ciudadanos, las mujeres y las personas esclavas fueron enteramente excluidas, obligando a que reclamaran sus derechos, apelando a la igualdad, a la Constitución y a la justicia de la Republica, y ya no a la piedad del rey (Garrido, 2004). 
Modelo de doble tensión para analizar las estrategias de reconocimiento pleno de las diversidades sexuales en los debates de ciudadanía - Claudia M. Hurtado-Caycedo

Este recuento parcial basta para desarticular el carácter aparentemente sólido, cohesionado y cristalizado de la ciudadanía ${ }^{2}$, y mostrar que se establece en la relación Estado-ciudadano, o mejor dicho, que la ciudadanía se forma y se reforma en la relación entre el Estado y los ciudadanos, agentes con múltiples habitus y capitales que negocian la relación y el poder que la figura les otorga.

En otras palabras, atender la noción de ciudadanía desde los estudios culturales permite desplazarla de la interpretación estática y unívoca del derecho, que la entiende como la calidad que adquieren los nacionales mediante el lleno de los requisitos, fundamentalmente el de haber cumplido cierta edad mínima, y que habilita a la persona para ejercer derechos políticos, así como la plenitud de sus derechos civiles, e indagar, por su carácter temporal, maleable y su potencial dinámico.

[...] que las ciudadanías se constituyen dinámicamente, avanzando o retrocediendo y no simplemente como una condición que se adquiere o se pierde, tal como se concibe en las nociones tradicionales de ciudadanía.

En este sentido la ciudadanía es un concepto dinámico y no solamente el resultado exclusivo de la acción del Estado, debido a que la visión institucional de ciudadanía es transformada cons-

\footnotetext{
2 Otro ejemplo que da cuenta de este carácter es la historia de la ciudadanía femenina en Colombia: fue apenas en 1932 cuando a las mujeres se les reconocieron los derechos civiles, en el Código Civil del mismo año. Más adelante, en 1954, se reconocieron los derechos ciudadanos de la mujer a través de la reforma constitucional aprobada por el Congreso. Sin embargo, esta reforma no les autorizó el sufragio. Dos años después, "se determinó que darle la oportunidad de voto al género femenino sería darle una legitimidad más amplia a la democracia, esto es debido a que las mujeres resultaban ser más del 50\% del censo electoral del país" ("Voto Femenino", 2010). Es importante hacer un paréntesis y mencionar la historia alternativa, que interpreta la determinación de conceder el voto a las mujeres como un interés político del Presidente Gustavo Rojas Pinilla, pues dicho sufragio le podría representar hasta un $50 \%$ de votos adicionales a su segunda reelección. Cualquiera que haya sido la razón, la reforma constitucional aprobada por el plebiscito del primero de diciembre de 1957 decretó una serie de modificaciones a la Constitución de 1886, entre ellas, el “artículo 1. Las mujeres tendrán los mismos derechos políticos que los varones" (Colombia, 1957).
} 
tantemente por procesos de producción, circulación y empleo estratégico y táctico de conocimientos socialmente pertinentes para reinventar la convivencia y el bienestar social. Estos procesos dan como resultado la coexistencia de varias ciudadanías entrelazadas y en constante negociación que se mueven entre perspectivas institucionales y expectativas y luchas individuales y colectivas. En sociedades como la colombiana, desgarrada por profundas desigualdades y por una concentración extrema del poder, la ciudadanía no se ejerce, sino que se conquista a través de la participación de los sujetos.

En este entrelazamiento aparecen diversas propuestas locales caracterizadas por su énfasis comunitario, por dinámicas sociales solidarias entre grupos fronterizos o colectividades a distancia y por la exaltación de las diferencias. Tales propuestas retan las relaciones modernas entre sujeto, Estado y territorio, y transforman los conceptos de ciudadanía, al proponer formas de organización social alternativas al marco del Estado-nación, y plantean un conjunto de principios mínimos que respeten las diferencias y promuevan las particularidades de grupos específicos (Grupo de Investigación Ciudadanías Incluyentes, en Vignolo, 2009: 41).

La ciudadanía establece la relación Estado - sociedad civil; segundo, es una cualidad que, tanto en el ámbito simbólico como en el jurídico, se negocia en esa relación; y tercero, que faculta al individuo para reclamar esa calidad de la ciudadanía integral conformada por la ciudadanía política, que garantiza los derechos políticos (el poder político de elegir o ser elegido); la ciudadanía civil, que garantiza los derechos civiles (libertad individual, libertad de la persona, de expresión, de pensamiento y religión, derecho a la propiedad y a establecer contratos válidos, y derechos a la justicia) y, finalmente, la ciudadanía social que garantiza los derechos sociales, económicos y culturales (el derecho a la seguridad, a un mínimo de bienestar económico, a compartir plenamente la herencia social y a vivir la vida de un ser civilizado conforme los estándares predominantes en la sociedad). 
Ahora bien, podríamos añadir una cuarta dimensión que ha sido reciente en los debates académicos, a saber, la ciudadanía sexual:

[...] aquella que enuncia, facilita, defiende y promueve el acceso a los ciudadanos al efectivo ejercicio de los derechos tanto sexuales como reproductivos y a una subjetividad política que no ha disminuido por las desigualdades basadas en características asociadas con sexo, género y capacidad reproductiva (Cabral, Crispan y Viturro en Lynd y Argüello, 2009: 13).

Me resulta interesante añadirla para pensar la llamada ciudadanía integral porque, por un lado, complejiza lo que entendemos por ciudadanía y derechos ciudadanos y, por otro lado, significa un nuevo lugar desde el cual posicionarse y demandar una ciudadanía más amplia y con más garantías.

Retomando, argumenté que las limitaciones en el proceso hacia la real aceptación de las diversidades son atribuibles, en mayor o menor medida, al hecho de que los reconocimientos de las diversidades se negocian preponderantemente en un campo político de tipo jurídico que, además, restringe la participación en el Estado. Dicho de otra forma, es un campo que reconoce la dimensión jurídica de la lucha y es fundamentalmente relativo a la institución estatal, en el que la lucha procura mantener los mismos recursos materiales y simbólicos en manos de los mismos agentes e instituciones.

A continuación, voy a analizar el potencial que tiene la Marcha LGTB para enmendar tales limitaciones e incluir el tema de las diversidades sexuales en los debates de ciudadanía. Concretamente, me interesa mostrar el potencial de la Marcha para ampliar el canon de la ciudadanía incluyendo las diversidades sexuales.

\section{La Marcha LGTB. El caminar como acción política}

Para comprender cómo la inclusión de las diversidades sexuales puede ampliar los límites que definen la ciudadanía podría anali- 
zar distintas acciones sociales. Una razón para escoger la Marcha es que en ella confluyen varias organizaciones. Otra, es que es una acción que con sus altibajos y a pesar de ser cambiante y dinámica, se ha mantenido en el tiempo. Pero fundamentalmente, me interesa analizar esta expresión porque apunta directamente al tema de la ciudadanía, cosa que ha pasado desapercibida. Ahora bien, ¿cómo se define una marcha?, ¿cómo se define el marchar?

Martha Cecilia García, investigadora y autora de trabajos sobre movimientos sociales en Colombia, ofrece una interpretación que me resulta particularmente interesante. Para ella, el caminar como acción política implica disrupción, resistencia, desafío y emancipación. Desde su lectura, cercana al modelo que propuse anteriormente, estas clases de acciones se acercan a la ciudadanía, a la vez que se alejan de los procedimientos y formas institucionales de participación política. Son repertorios de lucha que desafían el sistema y permiten captar señales sobre sus situaciones conflictivas. El caminar, añade, saca a la luz pública problemas que tradicionalmente son administrados en una relación Estado-actor; de esta manera son reconocidos y atendidos por una comunidad más amplia "que no necesariamente debe asumir como propios los valores y planteamientos específicos de los protagonistas de la acción, sino permitirles disfrutar de sus libertades y derechos." (García, en Vignolo, 2009: 307).

El caminar con sentido político al que García se refiere, exige hacer inversiones organizativas y emocionales que llevan a una mejor comprensión de las necesidades propias y la construcción de sujetos sociales que tengan claridad, entre otras cosas, de las relaciones de sus acciones colectivas al confrontar a otros actores sociales y al Estado, a la vez que revela las posibilidades de agencia de los sujetos en la constitución del mundo social:

Al caminar juntos en un espacio público, los manifestantes ponen en evidencia su existencia como actores colectivos, sus identidades sociales; visibilizan tanto sus intereses políticos y culturales como los discursos hegemónicos que pretenden contradecir, a través de variadas estrategias retóricas, 
imágenes, metáforas y maneras específicas de ubicarse en el espacio público (García, en Vignolo, 2009: 310).

En síntesis, se trata de acciones colectivas que desatan batallas semióticas en las que se acuerdan de manera conjunta las condiciones del campo social. Concluye García que la bondad de estas acciones colectivas radica en sus posibles aportes a la ampliación de la democracia y a la puesta en escena de nuevas formas de ciudadanía, según el impacto y la eficacia política que puedan alcanzar las propuestas, determinados no sólo por sus logros en el trámite de sus exigencias, sino también cómo y qué tan ampliamente y qué tan apropiadamente circulan sus exigencias, discursos y prácticas en diversos espacios, entre los que señala la política formal y la "esfera pública plebeya" (García, en Vignolo, 2009).

Coincido con García en su comprensión del caminar como una batalla semiótica y a la vez performativa. En este caso, entiendo que la Marcha LGBT libra una batalla semiótica para definir qué es la ciudadanía y lo hace recurriendo a diversos repertorios de lucha que incluyen las performancias. Mi lectura de la Marcha subraya además, que estamos frente a un evento que amplía la ciudadanía en la medida en que procura la incorporación de las diversidades sexuales.

\section{La Marcha de la Ciudadanía Plena LGBT: para ampliar el canon de la ciudadanía diversa}

Este apartado está dedicado a mostrar la potencia de la Marcha LGBT; con ella me refiero a las diferentes marchas que la población LGBT, colectivamente organizada, realizó transitoriamente en la primera década de los años ochenta y que retomó ininterrumpidamente a partir de 1997. Para llevar a cabo esta tarea retomaré el modelo de doble tensión que instala el análisis de la ciudadanía entre el Estado y la sociedad civil, por un lado, y el ámbito simbólico y jurídico, por otro. Me interesa mostrar cómo el caminar de las personas LGBT, en sus casi 30 años de organización colectiva, ha tenido la potencia para poner en tensión uno y 
otro eje. Atenderé someramente el eje constituido por la Sociedad Civil y el Estado, para concentrarme en el desplazamiento del ámbito jurídico al simbólico. Para finalizar explicaré sucintamente la manera en que la Marcha también intenta llevar el debate de la ciudadanía del ámbito simbólico al jurídico.

\section{Del Estado a la sociedad civil: solidaridad, cohesión y carnaval para exceder al Estado}

La constante vulneración de los derechos fundamentales de la comunidad -que en Colombia se dio en la forma de allanamientos a los sitios de reunión, retención policial (que incluía maltrato y crímenes sexuales) y desaparición, y otros crímenes de odio que llegaban hasta el asesinato "por marica"; llevó a que en la primera mitad de la década de los ochenta, un grupo de veinte hombres homosexuales decidiera salir a caminar, como acto de solidaridad, "porque al compañero lo volvieron mierda" (Entrevista realizada por Hurtado Caycedo, 2010).

Ese caminar se vale de la cohesión y la solidaridad para dirigirse políticamente, y ya no al Estado represor, sino a los sectores de la sociedad civil afines a su lucha:

No éramos muchos, inicialmente éramos dos filas o tres de personas por la calle, no a lo largo sino a lo ancho caminando, cogidos de los brazos. Uno iba gritando pero no tan duro, con miedo y terror, consignas políticas con las que exigíamos el derecho a que el Estado educara a los padres. Después de eso y a causa del temor, no nos encontrábamos sino varios días después (Entrevista realizada por Hurtado Caycedo, 2010).

Más adelante, en 1997, la Marcha adquirió un carácter celebratorio que perseguía tres misiones: el fortalecimiento de la identidad sexual, la apropiación del espacio social y la promoción de la participación activa. Si bien es cierto que puede tratarse de un culturalismo excesivo que corre el riesgo de desatender el carácter político de las reivindicaciones en torno a la identidad sexual, también es cierto que una vez que el Estado despenalizó 
la Marcha LGBT y esta optó por adquirir un carácter carnavalesco, la misma se dirigió a la sociedad civil para ratificarle que logró exceder el ámbito estatal así como ir más allá de las concesiones de la ley. Podríamos decir que, en conjunto, las tres misiones del Carnaval del Orgullo Lésbico y Gay, por su "excesivo culturalismo", lograron llevar a la sociedad civil discusiones de la ciudadanía que, aparentemente, habían sido resueltas en el ámbito jurídico del Estado. Marchar se convirtió más en una reafirmación vistosa y bulliciosa de sus derechos frente a la sociedad civil, que en un caminar silencioso y agradecido con el Estado, un caminar que no quiere incomodar.

\section{De la sociedad civil al Estado: resignificando la ciudad con historias sexualmente diversas}

Anualmente la Marcha recorre la Carrera Séptima, una vía arteria principal y de gran importancia histórica, simbólica, política y económica para la ciudad; y ocupa la Plaza de Bolívar, el corazón de la capital del país, enmarcada por instituciones de trascendencia histórica, religiosa y política, como práctica que reclama el espacio público y, simultáneamente, cambia la ciudad al convertirse en parte de su historia. En esta línea, Moreno afirma que "se trata de entender el caminar como una forma de intervenir conscientemente el paisaje. Es interrumpir la percepción por la que estamos dominados y a la que estamos acostumbrados normalmente, como un flujo de conciencia que cambia nuestra percepción de la historia y de nuestra identidad" (Moreno-Hoffman, en Vignolo, 2009: 302).

En pocas palabras, ocupando espacios y lugares de la historia oficial de la nación, la Marcha reclama el uso del espacio público y logra resignificar la ciudad con historias sexualmente diversas; con ello, vuelve a interpelar al Estado para ampliar los límites de la ciudadanía de modo que incluya a las diversidades sexuales. 


\section{De lo jurídico a lo simbólico: subvirtiendo las instituciones que recluyen las sexualidades}

Como he venido diciendo, la noción de ciudadanía suele referirse a una calidad que habilita la participación en el campo jurídico. Sin embargo, la Marcha la ha concebido de una manera que permite arrastrar el debate al terreno de la sociedad civil, constituyéndola en un campo de lucha simbólica. Es decir, la Marcha retoma la ciudadanía como un ámbito de cambio que le pertenece a la sociedad civil para definir lo que cuenta como "político" tanto en su dimensión simbólica como en la jurídica, al subvertir las instituciones que recluyen las sexualidades, a la vez que las complementa. A continuación me centraré en cómo su realización en el día domingo, desplaza el debate entre lo simbólico y lo jurídico.

Como se sabe, la arraigada tradición cristiana dispone de este día para la celebración de la resurrección de Jesús, un día destinado "al Señor", al descanso y a la asistencia a los servicios dominicales. Tras la revolución francesa, el descanso del domingo apareció paulatinamente en el derecho laboral de países de tradición cristiana y en la actualidad está admitido en casi todas las legislaciones. Con su realización en este día, la Marcha interpela a tres instancias de gran legitimación: a la Iglesia, a la familia y a la ciudadana o ciudadano común, enmarcándose en el significado del domingo para subvertirlas.

El caminar de personas LGBT reclama un uso diferenciado del espacio público, tensionándolo al albergar las prácticas, expresiones y sentido de otras formas de vivir el cuerpo, y convertirlo en testigo de las protestas y reclamos y en escenario de esta ciudadanía en formación. De esta manera, por un lado, se distancian de los significados históricos, religiosos y políticos tradicionales de la Séptima y de la Plaza de Bolívar, y por el otro, propone uno alternativo. Pensemos por ejemplo que la Marcha, con la Catedral como testigo, introduce significados, prácticas y 
cuerpos contrarios a los de la Iglesia. Pero además, con su realización el día de la liturgia, enfrenta de manera respetuosa a los feligreses asistentes a los servicios de las 12:00 hrs pm y de la 1:00 hrs. pm, con realidades que no pueden negar: la conglomeración de aproximadamente 35.000 personas alrededor de la Marcha de 2004 (Mesa de trabajo LGBT de Bogotá, 2010). ¿Esto tiene algún impacto en los feligreses?, ¿los hace confrontar el rechazo de la Iglesia con la magnitud y las características de la manifestación?, ¿tiene el efecto de ser la conversación del almuerzo?

Así mismo, apela a la familia. Así lo muestra el testimonio de Jaime, un sincelejano que hacía plan dominguero junto a su familia en la Plaza de Bolívar y compartía el espacio con la Marcha de 2005: "Si en el mundo hay espacio para todos, ¿por qué no en este parque?" (El Tiempo 2005, sección 1:14).

El cuestionamiento encuentra respuesta en los comunicados de las Marchas:

Algunas personas nos han preguntado cómo salir [...] a la marcha [...] Siendo heterosexual o invitando a que personas de esa orientación nos acompañen, al fin de cuentas siempre hemos estado rodeadas y rodeados de ellas y ellos, en nuestro núcleo de familia biológica o social o neofamilia, en nuestro trabajo, en nuestra cotidianidad; es más, algunos de nosotros nos identificamos socialmente de esa forma, con ese ropaje (Rincón Perfetti, en acta inédita).

Sin embargo, el potencial del interrogante generado por la convivencia no se queda allí. Pensemos por ejemplo en la anécdota que me contó Marilyn F. (Entrevista realizada por Hurtado Caycedo, 2010), transformista, quien fue aproximada en la marcha de 2010 por un padre de familia que le pidió que sostuviera a su hijo y le diera un beso para la foto. Para ella, se trató de una experiencia grata. La celebración de la marcha el domingo deja abierta la pregunta: ¿Por qué no cabemos todas y todos?, ¿por qué no en este parque?, ¿por qué no en la ciudad? Lo que quiero señalar es que la convivencia da lugar a una serie de posibilidades que escapan al control jurídico previsto por el Estado y la Iglesia. 
Pero no podemos dejar escapar aún otra consideración y es que, con todo lo anterior, la Marcha simbólicamente está tensionando el ámbito privado, en el que se mantiene recluido el hogar, controlado por el padre y la Iglesia; y el público, al que pertenece la ciudad, y es controlado por el Estado con un gravísimo intervencionismo por parte de la Iglesia, al evitar que la sexualidad y las sexualidades diversas sigan siendo recluidas en el primero.

Finalmente, al celebrar la Marcha el día domingo el sector se distancia de apelar a los trabajadores que, al estar en servicio de una entidad, se ven obligados a ajustar su comportamiento moral o a regular sus opiniones según los valores de sus empleadores. Así, se crea un escenario simbólico en el que ya no el trabajador, sino el ciudadano o ciudadana común tiene la libertad de reafirmar su propia identidad sexual y elegir su postura y participación. Así quedó recogido en las memorias del Proyecto Agenda:

[...] podemos contarles que uno de los policías que ayudó a la escolta de protección en el desfile, al despojarse de su uniforme luego de haber terminado labores, se dirigió a la fiesta central y se dispuso a disfrutarla en pleno (Acta inédita, 2000).

Así mismo, al realizarse el día del descanso, evita entorpecer el funcionamiento de la ciudad y se suma a la recreación y al deporte, compartiendo otras formas de aprovechar el espacio público, en las que se puede incomodar a quienes no están involucrados tanto como generar solidaridades:

Después de la ciclovía muchos de los que salieron a hacer deporte se quedaron para ver el desfile, y al paso de los dragqueen y de los gays disfrazados se oyeron aplausos (El Tiempo, 2005, sección 1: 14).

En conjunto, celebrar la Marcha el domingo evoca una serie de significados más allá de lo jurídico, que interpelan ya no al Estado sino a la sociedad civil, dándole la posibilidad de subvertir las instituciones que recluyen las sexualidades en la heteronormatividad; con estos significados además, interpela a la sociedad civil con una serie de interrogantes sobre las diversidades sexua- 
les, le ofrece la posibilidad de solidarizar con las personas cuyas vivencias de la sexualidad desbordan los parámetros heteronormativos y, en el mejor de los casos, le da potencia para ampliar la noción de ciudadanía con nuevos significados.

Con recursos como el flyer "detén la transfobia" ${ }^{3}$ el cual incluye información sobre qué es este fenómeno, facilitando ejemplos como la falta de legislación en el tema; se intenta responder a comentarios como el de Lucía, una vecina de 75 años, habitante del barrio Juan Rey: "Esos señores vestidos de mujer me parecen lo más deshonesto del mundo". La afirmación fue recogida en un artículo del periódico el Tiempo que mencionaba su indignación (El Tiempo, 2009, sección 1:12).

Recursos como éstos son oportunos para debatir en un ámbito simbólico la discriminación de la población LGBT y, también, para transformar la sociedad civil en general, de modo que supere su desconocimiento y el temor a lo diferente.

\section{De lo simbólico a lo jurídico: imputando a la sociedad civil para que cumpla la ley}

Finalmente no podemos obviar que las organizaciones de la Marcha, muchas veces, asumen la responsabilidad de construir una ciudadanía más amplia que incorpore las diversidades sexuales en el ámbito jurídico.

Por ejemplo, en respuesta a lo acontecido en el Colegio Leonardo da Vinci de Manizales, en el año 2008, donde se les negó el derecho a la matricula a dos niñas que se autoproclamaron lesbianas, una de las organizaciones participantes repartió un folleto, acompañado de lápices, con la proclama: "Por escuelas sin

\footnotetext{
3 Santamaría Fundación, cuya misión es difundir y defender la igualdad de derechos, el respeto, la equidad y la inclusión social por y para la población LGBT, teniendo como base de su accionar social la ciudadanía, salud, educación, cultura y bienestar social integral (Santamaría Fundación, 2010).
} 
prejuicios" $^{\prime 4}$; este informa sobre los hechos de discriminación y los efectos de éstos, a la vez, que aclara cuáles son los derechos de los estudiantes diversos sexualmente y estipula cómo se debe proceder en situaciones de discriminación; el folleto además invita a denunciar casos similares.

En otras palabras, la Marcha con esta estrategia de Colombia Diversa, devuelve a manos de la sociedad civil parte de la responsabilidad de adoptar la ley.

\section{Conclusión}

En el encuadre de la doble tensión para analizar las estrategias de reconocimiento pleno de las diversidades sexuales en los debates de ciudadanía, identifico varios de los desplazamientos de la Marcha: exceder al Estado con la solidaridad, la cohesión y el carnaval propios de la sociedad civil; resignificar con historias sexualmente diversas los lugares que la sociedad civil identifica como propios de la historia oficial del Estado; subvertir las instituciones que recluyen las sexualidades, llevar la discusión de la ciudadanía del ámbito jurídico al simbólico y, finalmente, la Marcha imputa a la sociedad civil para que cumpla con la ley, de modo que vuelve a arrastrar la discusión de la ciudadanía del ámbito simbólico al jurídico. En definitiva, la Marcha LGBT tiene la potencia para ampliar la noción de ciudadanía logrando que incluya las diversidades sexuales.

\footnotetext{
4 Colombia Diversa, una organización no gubernamental que trabaja por el pleno reconocimiento y el ejercicio de los derechos humanos de las personas LGBT.
} 
Modelo de doble tensión para analizar las estrategias de reconocimiento pleno de las diversidades sexuales en los debates de ciudadanía - Claudia M. Hurtado-Caycedo

\section{Bibliografía}

Colombia, Corte Constitucional (2011): Sentencias (Sentencia C-577). Bogotá: M.P.: Mendoza Martelo, G.E. Bogotá.

Colombia, Presidencia de la República (1957, octubre 4): Decreto número 247 sobre plebiscito para una reforma constitucional. Bogotá.

Davis, Ángela (2010): Racismos de Estado y complejo industrial de las prisiones [Conferencia], Cátedra inaugural de los posgrados en estudios de género, Universidad Nacional de Colombia. Bogotá.

El Tiempo (2009, junio 29): “Los colores de la Marcha LGBT (2009, junio 29). Pp. 1-12, Bogotá.

El Tiempo (2005, julio 4): "Somos visibles sólo para pagar impuestos." (2005, julio 4). Pp. 1-14, Cartas a la Defensora.

Garrido, Margarita (2010): "Palabras que nos cambiaron: Lenguaje y Poder en la independencia". Recuperado en julio 6 de 2010 desde: http:/ / www.lablaa.org/palabras-que-nos-cambiaron/texto004a.html.

Garrido, Margarita (2010): "El voto femenino". Recuperado en agosto de 2010 desde: http://www.lablaa.org/blaavirtual/ayudadetareas/poli/poli84.htm.

Lemaitre Ripoll, Julieta (2009): El derecho como conjuro. Fetichismo legal, violencia y movimientos sociales. Bogotá, Siglo del Hombre y Universidad de los Andes.

Lind, A. y Argüello Pazmiño, S. (2009): “Activismo LGBTQ y ciudadanías sexuales en el Ecuador". Íconos. Revista de Ciencias Sociales, nº 35 (pp. 97-101), en: http:/ / redalyc.uaemex.mx/ redalyc/src/inicio/IndA.

Matrimonio Igualitario (2011): Derecho Comparado. Recuperado en septiembre de 2011, desde: http:/ / www.matrimonioigualitario.org

Mesa de trabajo LGBT de Bogotá (2010, junio 27): “XIV Marcha de la ciudadanía plena de personas LGBT de Bogotá". Recuperado en agosto de 2010, desde: http:/ / www.scribd.com/ doc/32685470/XIV-Marcha-por-la-Ciudadania-Plena-delas-personas-LGBT\#source:facebook.

Noguera Rojas, M. (2011): “Familias diversas, familias felices, y ahora constitucionales. Razón Pública". Recuperado en: http:/ / 
razonpublica.com/index.php/politica-y-gobierno-temas27/2262-familias-diversas-familias-felices-y-ahora-constitucionales.html.

Proyecto Agenda (Inéditas). Actas reuniones años 2000 -2009.

Hurtado Caycedo y Claudio M. (2010): Entrevista personal con G. Rodríguez. Bogotá, mímeo.

Santamaría Fundación (2010): Recuperado en agosto de 2010, desde: http://santamaria.ya.st/.

Szurmuck y Mckee (coord.) (2009): Diccionario de estudios culturales latinoamericanos. México, Siglo XXI.

Vignolo, Pablo (edit.). (2009): Ciudadanías en escena. Performance y derechos culturales en Colombia. Bogotá, Universidad Nacional de Colombia, Facultad de Ciencias Humanas. 